Williams, R. E. O., Hirch, A. \& Cowan, S. T. (1953). J. gen. Microbiol.8, 475-480

\title{
Aerococcus, a New Bacterial Genus
}

\author{
By R. E. O. WILLIAMS, ANN HIRCH AND S. T. COWAN \\ Air Hygiene Laboratory, Public Health Laboratory Service, and the National \\ Collection of Type Cultures, Colindale Avenue, London, N.W. 9
}

SUMMARY: The generic name Aerococcus is proposed for a group of aerobic Grampositive cocci that are commonly found in the air of occupied places and in dust. The most characteristic features of the organisms are ability to grow in the presence of $40 \%$ bile and to produce greening on blood agar. They are catalase-negative, and do not show chain-formation in culture.

For the collection and recognition of mouth streptococci from air a selective culture medium was devised (Williams \& Hirch, 1950) which had the composition: serum agar, $100 \mathrm{ml}$.; sucrose, 5 g.; potassium tellurite, $1.0 \mathrm{mg}$.; crystal violet, $\mathbf{0} \cdot 25 \mathrm{mg}$. This selective medium inhibits the growth of diphtheroid and coliform organisms and practically all strains of those Gram-positive cocci that would ordinarily be regarded as staphylococci. It permits good growth of most streptococci, including Streptococcus pyogenes, viridans-type streptococci and enterococci. However, in air samples from occupied rooms, about $70 \%$ of the colonies are not of typical streptococci, but are of a Gram-positive coccus that does not appear to have been adequately described in the literature. We consider that this organism has sufficient points of difference from both streptococci and staphylococci to justify its being placed in a new genus for which we propose the name Aerococcus.

\section{DESCRIPTION OF AEROCOCCUS}

\section{Cultural and morphological characteristics}

After 18-24 hr. incubation at $37^{\circ}$ on blood agar the colonies of Aerococcus are $\mathbf{0 . 5 - 2 . 0} \mathrm{mm}$. in diameter, semi-transparent, white or grey, and surrounded by a wide or narrow zone of greening (Pl. 1, fig. 1); with some strains the centre of the area of greening may be very dark. The organisms grow well on nutrient agar with or without $0.5 \%$ glucose, and on serum agar, chocolate agar and blood agar. The colonies are larger on blood agar than on the other media; the addition of serum or glucose to nutrient agar results in only slight increase in colony size. Growth is not enhanced, and may be slightly decreased, by incubation anaerobically or in air with $30 \%$ carbon dioxide. The green discoloration round colonies on blood agar or chocolate agar is much decreased in depth and area when the cultures are incubated anaerobically. On all these media growth takes place at $22^{\circ}$, the colonies taking about $42 \mathrm{hr}$. to reach the size reached in $18 \mathrm{hr}$. at $37^{\circ}$. There is no growth on potato. In nutrient broth or peptone water growth is very poor, but it is considerably increased by the addition of $0.5 \%$ glucose.

Microscopically the organisms are round Gram-positive cocci 1-2 $\mu$. in 
diam., usually staining deeply, arranged in pairs or irregular clusters (Pl. 1, fig. 2); different strains vary considerably in the size of the cells and in their arrangement. Chains are not formed on solid or in fluid media and the paired cocci do not show elongation along the axis joining their centres, as is seen with pneumococci.

The biochemical activities of twelve representative strains of these organisms are given in Table 1.

Table 1. Cultural characteristics of aerococci

$\begin{array}{cc}\text { Aerococcus } & \\ \text { viridans : } & \text { No. positive of } \\ \text { NCTC 8251 } & \text { 12 strains tested } \\ + & 12 \\ + & 12 \\ - & \\ + & 0 \\ - & 11 \\ + & 0 \\ - & 12 \\ + & 0 \\ - & 12 \\ - & 0 \\ \pm & 0 \\ - & 12 \\ + & 0 \\ + & 12 \\ + & 12 \\ + & 10 \\ + & 5 \\ - & 12 \\ 5 \cdot 5-5 \cdot 8 & 4 \\ - & 12 \\ - & 0 \\ & 0\end{array}$

Greening on blood agar

Growth in the presence of $40 \%$ bile

Growth in the presence of $1 / 2500$ potassium tellurite on

the medium of Anderson et al. (1931)

Growth at $\mathrm{pH} \mathbf{9 \cdot 6}$

Growth at $45^{\circ}$

Resistance to $60^{\circ}$ for $30 \mathrm{~min}$.

Reduction of $0.1 \%$ methylene blue in milk

Acid but no clot in litmus milk

Liquefaction of gelatin

Hydrolysis of: Arginine

Aesculin (in solid medium)*

Acid produced from: Glucose

Starch $1 \%$ (in solid medium)

\section{Maltose \\ Lactose \\ Mannitol \\ Sucrose \\ Raffinose}

Final $\mathrm{pH}$ value in $1 \%$ glucose broth

Catalase production

Coagulase production

* $0.10 \%$ aesculin was incorporated in the $40 \%$ bile agar with $0.05 \%$ ferric citrate as indicator. After $24 \mathrm{hr}$. incubation the medium was unchanged, but after another day on the bench some hydrolysis of the aesculin, indicated by blackening of the plate, had occurred.

Acid and formamide extracts of many strains have been tested for precipitinogen reacting with antisera to Lancefield Group D streptococci but none has been found, even after ethanol precipitation (Shattock, 1949). An attempt was made to prepare an antiserum against one typical strain but it did not react with extracts of the vaccine strain, other aerococci, or enterococci. The organisms tend to give rather granular suspensions in saline or broth; none of six strains giving smooth suspensions was agglutinated by antisera to various Lancefield groups of streptococci or to Staphylococcus aureus.

In many respects the organisms resemble streptococci, particularly enterococci (see Table 2). Thus they either fail to produce catalase or produce only the merest trace of it; they are benzidine-positive; they flourish on serum agar containing $40 \%$ bile and on agar containing $1 / 400,000$ crystal violet and $1 / 100,000$ potassium tellurite. 
On the other hand, microscopically the organisms do not resemble streptococci. Although it is true that some strains of undoubted streptococci show few or no chains, we do not think that one could ever examine preparations from several thousand streptococci without seeing any with definite chain formation. But this is the case with the aerococci.

Table 2. Comparison of biochemical reactions of Aerococcus viridans| with those of Streptococcus faecalis and Str. bovis

Growth on $40 \%$ bile

Resistance to $60^{\circ}$ for $30 \mathrm{~min}$.

Growth at $\mathrm{pH} 9 \cdot 6$

Growth at $45^{\circ}$

Growth on tellurite medium

Hydrolysis of arginine

Reduction of $0 \cdot 10 \%$ methylene blue in milk

Litmus milk

Final $\mathbf{p H}$ value in $1 \%$ glucose broth

$\begin{array}{ccc}\begin{array}{c}\text { Aerococcus } \\ \text { viridans }\end{array} & \begin{array}{c}\text { Str. faecalis } \\ \text { and variants }\end{array} & \text { Str. bovis } \\ + & + & + \\ + & + & - \\ + & + & - \\ - & + & + \\ - & + & - \\ - & + & - \\ - & + & \text { Acid } \\ \text { Slight acid } & \text { Reduction } & \mathbf{4} \cdot 0-4 \cdot 8\end{array}$

Shaw, Stitt \& Cowan (1951) have already pointed out that the aerococci, which they referred to as their ' $\alpha$-group', seem to be distinguished from the staphylococci by the absence or extreme poverty of catalase production, by the fact that the colonies are semi-transparent, and by the fact that on blood agar they are surrounded by a definite zone of green coloration. We consider, therefore, that they constitute a distinct genus in many ways intermediate between Staphylococcus and Streptococcus; and from the source in which we first observed them we propose as the generic name, Aerococcus. The genus is probably more closely related to Streptococcus than to Staphylococcus, and should be placed in the same family as Streptococcus.

The genus is defined as follows:

Aerococcus. Constant characteristics. Gram-positive, non-motile cocci occurring in pairs or irregular clusters, usually small. Aerobic and facultatively anaerobic; growth occurs on solid media at $22^{\circ}$ almost as well as at $37^{\circ}$, but not at $45^{\circ}$. Colonies on blood agar incubated aerobically at $37^{\circ}$ for 18 $\mathbf{2 4} \mathrm{hr}$. are semi-transparent and surrounded by a zone of green colour. Growth is not inhibited by $40 \%$ bile, nor by $1 / 400,000$ crystal violet. Arginine is not hydrolysed. The organisms survive heating to $60^{\circ}$ for $30 \mathrm{~min}$. and grow at pH 9.6. Acid and formamide extracts do not react with sera prepared against Lancefield Group D streptococci.

Variable characteristics. Table 1 indicates that some of the carbohydratefermentation activities vary from strain to strain. A representative strain isolated from the air of an occupied room has been deposited in the National Collection of Type Cultures as the type strain (NCTC 8251), with the name Aerococcus viridans n.sp. Its characteristics are included separately in Table 1. 


\section{Ecology}

Our attention was first drawn to these organisms by the fact that they confused our search for air-borne viridans streptococci; they constituted the great majority of the colonies on plates of the crystal-violet potassium tellurite medium that was employed. The following figures indicate their general prevalence in the air of occupied places, as determined by counting plates exposed in a slit-sampler (Bourdillon, Lidwell \& Thomas, 1941):

\begin{tabular}{|c|c|c|c|}
\hline & Colonie & eu.ft. air & \\
\hline & Aerococci & $\begin{array}{c}\text { Total } \\
\text { streptococci }\end{array}$ & $\begin{array}{c}\text { No. of } \\
\text { observations }\end{array}$ \\
\hline Occupied schoolrooms & $6 \cdot 92$ & $1 \cdot 18$ & 763 \\
\hline Boot and shoe factories & $2 \cdot 00$ & 0.52 & 23 \\
\hline Large clerical offices & $0 \cdot 83$ & $0 \cdot 15$ & 90 \\
\hline
\end{tabular}

The organisms are also very common in floor-dust from occupied places, on clothing, and in dust from yards and streets in London. In all these sites it is probable that they constitute some $5-10 \%$ of the total aerobic flora that will grow on ordinary nutrient media at $37^{\circ}$. In the schoolrooms we have been able to show that the count of the aerococci in the air varies to some extent with the amount of activity by the occupants.

We have not been able to discover any obvious human source of the aerococci found in the environment. Organisms of this sort are present only in very small numbers, if at all, in the upper respiratory tract of normal persons, and they are by no means common in faeces. They may be present in rather small numbers on normal skin. We have not made any systematic search for aerococci on animals, but their frequency in occupied rooms from which animals are largely excluded, and on clothing, suggests that this is not a likely source.

\section{DISCUSSION}

Despite the large numbers of the organisms which we describe as aerococci that are present in the environment, they do not appear to have been well described in the literature. Buchbinder, Solowey \& Solotorovsky (1938), who studied bacteria from air samples in occupied places, described what we presume to be the same organisms as 'putative streptococci', largely because of the similarity of their fermentation reactions to those of typical streptococci. On the other hand, Rabl \& Seelemann (1949) described similar organisms from various lesions in humans as 'diplokokken', and seem to have regarded them as distinct from streptococci. Duguid \& Wallace (1948) noted $\alpha$ haemolytic micrococci as common in bacteriological samples from clothing, and Bourdillon, Lidwell \& Lovelock (1948) found micrococci on crystalviolet blood agar plates, which were a source of confusion in a search for $\alpha$-haemolytic streptococei in air samples. A number of similar organisms were deposited in the National Collection of Type Cultures by Dr C. L. Hannay, who had isolated them from dairy equipment and had noted their extreme resistance to disinfection by hypochlorite. 
Several extensive studies of enterococci have been reported (e.g. Houston, 1905; Dible, 1921), and it might be thought that aerococci would have been included in these descriptions. However, we can find no direct reference to organisms with the characteristics that we describe. This is partly due to the fact that many of the tests by which we distinguish aerococci from enterococci are of relatively recent introduction. Moreover, in faeces, which were the source of most of the strains studied by Houston and by Dible, aerococei are not common, and any worker studying streptococci would tend to discard organisms that, microscopically, resembled micrococci rather than streptococci. The organisms were brought to our notice when we were studying the flora of the air in which they are common, and were employing a particular selective medium. We feel that when aerococci have been noticed in the past, they have probably been regarded as morphologically atypical enterococci. It is the fact of having handled so many cultures that gives us some confidence in describing them as different from enterococci.

The reasons for excluding the aerococci from the genus Staphylococcus were given by Shaw et al. (1951). The problem is to decide whether they are sufficiently closely related to the streptococci, particularly enterococci, to be classed with them. The absence of catalase production would suggest that they might be streptococci, but morphologically they do not resemble streptococci. The morphological criterion is admittedly unsatisfactory and could not be given much weight had our experience of the organisms been limited to the examination of a few strains, or of old laboratory strains. But during the last few years we have examined many thousands of films made from colonies, and many hundreds of blood agar cultures. We have no doubt that the aerococci form a group worthy of separate recognition, and we do not feel that they resemble the streptococci sufficiently to be classed with them.

It remains to be shown how the aerococci differ from species of Pediococcus Balcke, which Shimwell (1948) regarded as streptococci. Pederson (1949) characterizes pediococci as Gram-positive, non-motile, catalase-negative cocci which tend to form packets of four but which may occur as single or paired cells. They are microaerophilic, produce a final $\mathrm{pH}$ value of $3 \cdot 25-3 \cdot 4$ in glucose broth, do not reduce nitrates to nitrites or liquefy gelatin. Aerococci differ from pediococci in that they do not normally form packets, they are not microaerophilic, and they do not form so much acid in glucose broth (final $\mathrm{pH}$ value $5 \cdot 0-5 \cdot 6$ ). Pederson's cultures of pediococci seldom utilized mannitol; Shaw et al. found $69 \%$ of their $\alpha$-group (aerococci) fermented this sugar, as did five of the twelve strains recorded in Table 1. Raffinose is fermented by nearly all pediococci but by only a third of aerococci. In addition aerococci tolerate crystal violet and potassium tellurite, which pediococci do not, and they produce marked greening on blood agar.

We are indebted to Dr B. C. Hobbs for the supply of staphylococcal antisera. 


\section{REFERENCES}

Anderson, J. S., Happold, F. C., Mcleod, J. W. \& Thompson, J. G. (1931). On the existence of two forms of diphtheria bacillus-B. diphtheriae gravis and $B$. diphtheriae mitis - and a new medium for their differentiation and for the bacteriological diagnosis of diphtheria. J. Path. Bact. 34, 667.

Bourdillon, R. B., Lidwell, O. M. \& Thomas, J. C. (1941). A slit sampler for collecting and counting air-borne bacteria. J. Hyg., Camb. 41, 197.

Bourdillon, R. B., Lidwell, O. M. \& Lovelock, J. E. (with others) (1948). Studies in air hygiene. Spec. Rep. Ser. med. Res. Coun., Lond. no. 262.

Buchbinder, L., Solowey, M. \& Solotorovsky, M. (1938). Alpha-haemolytic streptococci in air. Their variant forms, origin, and numbers per cubic foot of air in several types of locations. Amer. J. publ. Hlth, 28, 61.

Dible, J. H. (1921). The enterococcus and the faecal streptococci: their properties and relations. J. Path. Bact. 24, 3.

Duguid, J. P. \& Wallace, A. T. (1948). Air infection with dust liberated from clothing. Lancet, ii, 845 .

Houston, A. C. (1905). Report on the bacteriological examination of (1) the normal stools of healthy persons; (2) the intestinal contents of sea-fowl and fish; and (3) certain of our public water supplies. 33rd Ann. Rep. of the Medical Officer to the Local Government Board for 1903-4. London.

Pederson, C. S. (1949). The genus Pediococcus. Bact. Rev. 13, 225.

Rabl, R. \& Seelemann, M. (1949). Über das Vorkommen bestimmter 'unvollständig haemolysiender' Streptokokken- und Diplokokkenarten bei Mensch und Tier sowie über ihre Bedeutung als Infektionserreger. Zbl. Bakt. (1 Abt. Orig.), 154, 186.

Shatтock, P. M. F. (1949). The streptococci of group D; the serological grouping of Streptococcus bovis and observations on serologically refractive Group D strains. J. gen. Microbiol. 3, 80.

Shaw, C., StitT, J. M. \& Cowan, S. T. (1951). Staphylococci and their classification. J. gen. Microbiol. 5, 1010.

ShIMwELL, J. L. (1948). A rational nomenclature for the brewery lactic acid bacteria. J. Inst. Brew. 54 (N.S. 45), 100.

Williams, R. E. O. \& Hirch, A. (1950). The detection of streptococci in air. J. Hyg., Camb. 48, 504.

\section{EXPLANATION OF PLATE}

Fig. 1. Colonies of aerococci on blood agar after $24 \mathrm{hr}$. incubation at $37^{\circ}(\times 4)$.

Fig. 2. Aerococci grown in nutrient broth for $24 \mathrm{hr}$, at $37^{\circ}$ and stained by Gram's method $(\times 2000)$.

(Received 5 December 1952) 
Journal of General Microbiology, Vol. 8, No. 3

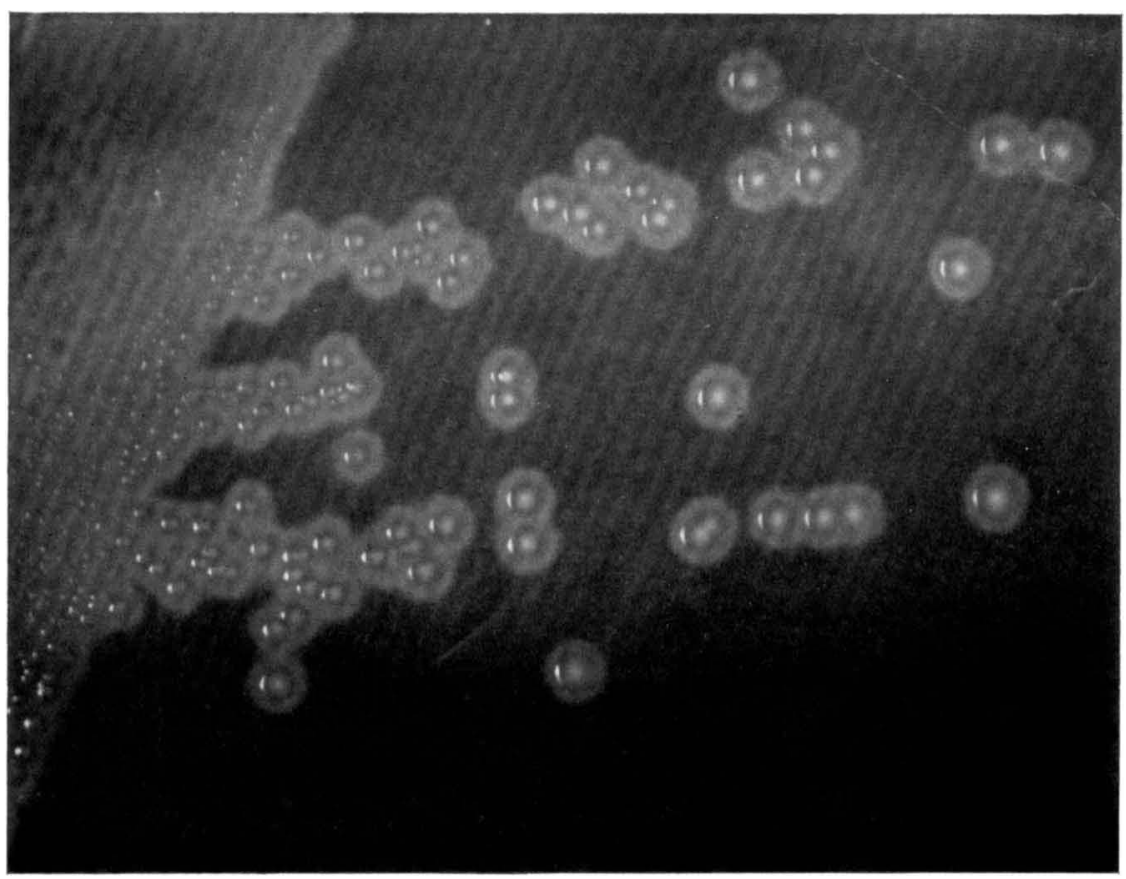

Fig. 1

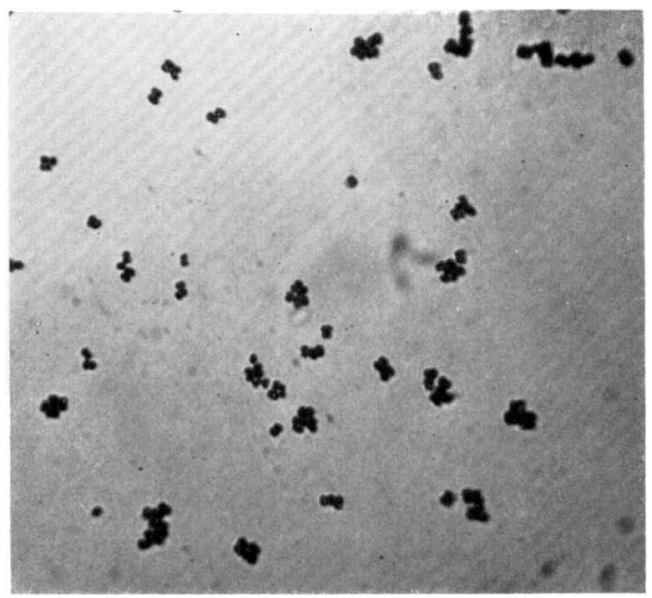

rig. 2

1R. E. O. Williams, A. Hurcir \& S. 'I'. Cowan-Alrococous, a NeW bacterial genus. Plate: 1 